\title{
DNA Hypermethylation Detected in Invasive Breast Cancer
}

\author{
By Vanda Repiska* \\ Zmetakova Iveta ${ }^{\dagger}$ \\ Kajabova Viera ${ }^{\dagger}$ \\ Smolkova Bozena ${ }^{\dagger}$ \\ Krivulcik Tomas ${ }^{\dagger}$ \\ Danihel Ludovit \\ Daniel Bohmer* \\ Fridrichova Ivana ${ }^{\dagger}$
}

\begin{abstract}
DNA methylation as an early event in breast carcinogenesis has been frequently studied in tumor samples. The aim of this study was to compare the relationship between DNA methylation levels of genes associated with invasivity and metastasising and aberrant protein expression. A total 55 healthy controls and 185 patients with primary breast cancer, as well as plasma and peripheral blood cells has been analysed by using pyrosequencing method. The expression of 11 proteins in paraffin-embedded biopsy was evaluated by immunohistochemistry. Genes containing CpG islands in promotor region were suggested for screening because they could be epigenetically regulated with high probability. DNA methylation of APC, ADAM23, CXCL12, ESR1, PGR B, CDH1, RASSF1A, SYK, TIMP3, BRMS1 and SOCS1 genes has been detected. DNA hypermethylation of tumor suppressor genes is tumor-specific and could be used for recognition of tumor cells. We observed higher methylation status for 4 genes (RASSF1A, APC, CXCL12 and ADAM23) from 11 genes evaluated in tumors. The highest promoter methylation level was $88 \%$, detected in RASSF1A
\end{abstract}

\footnotetext{
*Institute of Medical Biology, Genetics and Clinical Genetics, Faculty of Medicine, Comenius University in Bratislava, University Hospital Bratislava, Slovak Republic.

†Department of Genetics, Cancer Research Institute of SAS, Bratislava, Slovak Republic. †Department of Genetics, Cancer Research Institute of SAS, Bratislava, Slovak Republic. ${ }^{\dagger}$ Department of Genetics, Cancer Research Institute of SAS, Bratislava, Slovak Republic. ${ }^{\dagger}$ Department of Genetics, Cancer Research Institute of SAS, Bratislava, Slovak Republic.

${ }^{\ddagger}$ Institute of Pathological Anatomy, Faculty of Medicine, Comenius University in Bratislava, University Hospital Bratislava, Slovak Republic

*Institute of Medical Biology, Genetics and Clinical Genetics, Faculty of Medicine, Comenius University in Bratislava, University Hospital Bratislava, Slovak Republic.

${ }^{\dagger}$ Department of Genetics, Cancer Research Institute of SAS, Bratislava, Slovak Republic.
} 
and APC genes. Variable expression profiles were identified in analyzed genes ranging from negative expression to high expression. We can conclude that the quantitative analyses of tumor DNA methylation in any of RASSF1A, ADAM23, CXCL12 and APC genes could have prognostic potential. Supported by the grant APVV-0076-10 - the Slovak Research and Development Agency and Research and Development Operational Programme (ERDF)-26240220058

\section{Introduction}

Breast cancer is one of the major health problem that affect 1676633 human worldwide. With this number, breast cancer is the leading cancer diagnosed in the women and is second only to lung cancer in terms of total fatalities [1]. Survival of breast cancer patients have increased tremendously over the last few decades. However, this applies only if the breast cancer is diagnosed at an early stage and is limited to the primary organ. Once breast cancer metastasizes to other organs, the therapeutic options are very limited and the success rate of managing such patients in clinics is dismal. Breast cancer is driven by progressive genetic changes and epigenetic abnormalities [2]. It includes changed patterns of histone modification, with resultant remodeling of structure of chromatin and hypo- and hypermethylation of DNA. These changes cause deregulation of the transcription activity of many genes. Epigenetic regulation is critical for normal growth and development and provides a layer of transcriptional control. Therefore, the evaluation of the cancer-specific methylation pattern changes in the promoter regions has an important potential to improve an early detection of cancer and prediction of therapy and prognostic response. The aim of this study was to compare the relationship between DNA methylation levels of 11 genes participated on growth signal transferring (APC, ESR1, PGR B, RASSF1A, SYK and SOCS1) and metastasis formation (ADAM23,CXCL12,CDH1, TIMP3 and BRMS1). Since the selected genes contain $\mathrm{CpG}$ islands in promotor area they are epigenetically regulated with a high probability. Moreover, in breast carcinomas the different levels of methylation of the genes concerned were observed, suggesting different reduction rates of protein products synthesis.

\section{Methods}

A total of 185 paraffin-embedded tumor tissue samples from non-familiar patients with primary breast cancer and 55 healthy controls as well as plasma and peripheral blood cells have been analysed by using highly quantitative method of pyrosequencing. Tumors obtained from Slovak patients were staged and graded according to the current WHO classification for breast neoplasms. DNA from paraffin-embedded tumor tissues was isolated by the MagneSil 
Genomic, Fixed Tissue System (Promega, Madison, WI), from peripheral blood cell by using a FlexiGene DNA kit (Qiagen, Hilden, Germany) and from plasma samples by using a QIAamp DSP Virus Kit (Qiagen, Hilden, Germany), according to the manufacturer's instructions. DNA methylation in 11 genes (APC, ESR1, PGR B, RASSF1A, SYK, SOCS1, ADAM23, CXCL12, $C D H 1, T I M P 3, B R M S 1)$ containing $\mathrm{CpG}$ islands in promoter region was evaluated after the sodium bisulfite-treatment of isolated DNA $[3,4,5,6]$. CpG islands in the promoter area flanking the transcription start site at 5'UTR were selected for each gene. Five to eight $\mathrm{CpG}$ sites were studied for each particular $\mathrm{CpG}$ island. In ESRlgene the methylation status for two regions in the promoter $\mathrm{A}$ and in the first exon was evaluated, completely $14 \mathrm{CpG}$ sites.

Pyrosequencing assays primer sequences and PCR conditions were taken from [7]. For ESR1 gene was designed additional set of the oligonucleotides for PCR amplification and pyrosequencing of the promoter A using PyroMark Assay Design software 2.0 (Qiagen, Hilden, Germany). PCR primers for ESRI promoter A region 2: F primer - GTTGGAGGTTAGGGAGTTTAGG, R primer - biotin- TCTAACCCCCACCCTACCCC. Sequence for pyrosequencing primer is GGGAGTTTAGGAGTTGG. PCR product size is $120 \mathrm{bp}$ and it is analysed other $9 \mathrm{CpG}$ sites.

A total $1 \mu \mathrm{g}$ of peripheral blood cells DNA was bisulfite converted using the CpGenome DNA Modification Kit (Chemicon, 150 Billerica, MA). Cell free DNAs from plasma $(2 \mu \mathrm{g})$ and tumor DNA $(2 \mu \mathrm{g})$ were modified according to the protocol of EpiTect Bisulfite Kit (Qiagen, Hilden, Germany). PCR reactions were provided using the PyroMark PCR Kit (Qiagen, Hilden, Germany) according to the manual instructions with several modifications [7]. PCR conditions for ESR 1 promoter A region 2 were modified for final PCR primer concentrations to $0.28 \mu \mathrm{M}$. The annealing temperature was modified to $58^{\circ} \mathrm{C}$ for 30 seconds (Table 1). Pyrosequencing was carried out using a PyroMark Q24 system and the PyroGold Reagent Kit (Qiagen, Hilden, Germany). The results of the analyses were evaluated using the PyroMark Q24 2.0.6. software (Qiagen, Hilden, Germany). Methylation data are presented as the percentage of average methylation in all $\mathrm{CpG}$ sites observed and were calculated for each sample and each gene. Protein expression in malignant breast tissues was detected with specific antibodies against 11 corresponding proteins. Statistical analysis was performed by SPSS statistics 15.0 software. 
Vol. 1, No. 2 Repiska et al: DNA Hypermethylation Detected in Invasive Breast Cancer

Table 1. The Composition and Profile of PCR reaction for A2 ESR1 Gene Promoter Amplification

\begin{tabular}{|c|c|c|c|}
\hline PCR components & $\begin{array}{c}\text { Concentration for } 25 \mu \mathrm{l} \\
\text { reaction }\end{array}$ & \multicolumn{2}{|c|}{$\begin{array}{c}\text { Volume for } 25 \mu \mathrm{l} \\
\text { reaction }\end{array}$} \\
\hline $\begin{array}{l}\text { Pyromark } 2 \mathrm{x} \\
\text { concentrated }\end{array}$ & 1x concentrated & \multicolumn{2}{|c|}{$12.5 \mu 1$} \\
\hline $\begin{array}{l}\text { Coralload 10x } \\
\text { concentrated }\end{array}$ & 1x concentrated & \multicolumn{2}{|r|}{$2.5 \mu 1$} \\
\hline Primer F & $0.28 \mu \mathrm{mol} / \mathrm{l}$ & \multicolumn{2}{|r|}{$0.7 \mu \mathrm{l}$} \\
\hline Primer R & $0.28 \mu \mathrm{mol} / \mathrm{l}$ & \multicolumn{2}{|r|}{$0.7 \mu 1$} \\
\hline $\mathrm{H}_{2} \mathrm{O}$ & & $6.6 \mu 1$ & $4.6 \mu 1$ \\
\hline DNA & & $2 \mu 1$ & $4 \mu 1$ \\
\hline PCR program & Temperature & Time & $\begin{array}{c}\text { Number of } \\
\text { cycles }\end{array}$ \\
\hline First denaturation & $95^{\circ} \mathrm{C}$ & $\begin{array}{c}15 \\
\min \end{array}$ & $1 \mathrm{x}$ \\
\hline Denaturation & $94^{\circ} \mathrm{C}$ & $30 \mathrm{sec}$ & \multirow{3}{*}{$45 \mathrm{x}$} \\
\hline Annealing & $58^{\circ} \mathrm{C}$ & $30 \mathrm{sec}$ & \\
\hline Extension & $72^{\circ} \mathrm{C}$ & $30 \mathrm{sec}$ & \\
\hline Final extension & $72^{\circ} \mathrm{C}$ & $\begin{array}{c}10 \\
\text { min. }\end{array}$ & $1 \mathrm{x}$ \\
\hline
\end{tabular}

PCR reactions contained $2 \mu \mathrm{l}$ sodium bisulfite-treated DNA for peripheral blood cells and $4 \mu \mathrm{l}$ sodium bisulfite-treated DNA for cfDNA and paraffinembedded tumour tissues.

\section{Results and Discussion}

DNA hypermethylation of tumor suppressor genes is tumor-specific process and could be used for tumor cells recognition. Bisulfite pyrosequencing was used to investigate DNA methylation profiles in formalin fixed paraffin-embedded tissues, blood cells and plasma samples in 185 patients with primary breast cancer. table 2 .

Clinical and histopathological characteristics of patients are summarized in 
Table 2. Clinico - Histopathological Characteristics of Patients

\begin{tabular}{|lcc|}
\hline & N $\mathbf{1 8 5}$ & Frequency (\%) \\
\hline Age & & \\
\hline$\leq 50$ & 40 & 21.6 \\
$>$ 50 & 145 & 78.4 \\
Histological type & & \\
\hline ductal invasive carcinoma & 155 & 83.8 \\
lobular invasive carcinoma & 24 & 13.0 \\
OTHER & 6 & 3.2 \\
Tumor size & & \\
\hline$\leq 20$ mm & 120 & 65.93 \\
$>20$ mm $\leq 50$ mm & 55 & 30.22 \\
$>$ 50 mm & 7 & 3.85 \\
Histological grading & & \\
\hline 1 & 25 & 13.7 \\
2 & 88 & 48.4 \\
3 & 69 & 37.9 \\
Lymph node status (LN) & & \\
\hline negative & 103 & 59.9 \\
positive & 69 & 40.1 \\
Tumor node metastases staging (TNM) & & \\
\hline I & 89 & 48.4 \\
II & 62 & 33.7 \\
III & 30 & 16.3 \\
IV & 3 & 70.6 \\
Estrogen receptor status (ER) & & \\
\hline negative & 29 & \\
positive & 132 & \\
Progesterone receptor status (PR) & & \\
\hline negative & 47 & \\
positive & 113 & \\
\hline & & \\
\hline
\end{tabular}

We observed higher methylation status in 4 genes (RASSF1A, APC, CXCL12 and ADAM23) from 11 genes evaluated in tumors. Average DNA methylation levels in tumor tissue were as follows: $38.57 \% \pm 25.76$ for RASSF1A gene, $23.73 \% \pm 22.38$ for APC gene, $9.36 \% \pm 10.58$ for the gene $A D A M 23$ and $11.83 \% \pm 12.01$ for the gene $C X C L 12$.The highest promoter methylation level was $88 \%$ detected in both RASSF1A and APC genes (Table $3)$. 
Table 3. Levels of DNA Methylation in Breast Cancer Patients and Controls

\begin{tabular}{|c|c|c|c|c|c|c|c|c|c|}
\hline \multicolumn{4}{|c}{ Controls } & \multicolumn{4}{c|}{ Patients } & \multicolumn{2}{c|}{ Patients } \\
\hline Genes & \multicolumn{1}{|c|}{ DNA from peripheral blood cells } & \multicolumn{1}{|c|}{ DNA from peripheral blood cells } & \multicolumn{2}{|c|}{ DNA from tumors } \\
\hline & $\mathbf{N}$ & $\begin{array}{c}\text { Mean } \\
(\boldsymbol{\%}) \pm \text { SD }\end{array}$ & Range $(\boldsymbol{\%})$ & $\mathbf{N}$ & $\begin{array}{c}\text { Mean } \\
(\boldsymbol{\%}) \pm \text { SD }\end{array}$ & Range (\%) & $\mathbf{N}$ & $\begin{array}{c}\text { Mean } \\
(\%) \pm \text { SD }\end{array}$ & $\begin{array}{c}\text { Range } \\
(\%)\end{array}$ \\
\hline APC & 55 & $1.31 \pm 0.57$ & $1-4$ & 184 & $2.11 \pm 1.03$ & $0-6$ & 185 & $23.73 \pm 22.38$ & $1-88$ \\
\hline ADAM23 & 55 & $2.13 \pm 0.39$ & $1-3$ & 185 & $2.44 \pm 1.00$ & $1-12$ & 185 & $9.36 \pm 10.58$ & $1-60$ \\
\hline CXCL12 & 55 & $2.35 \pm 0.51$ & $1-3$ & 185 & $2.85 \pm 1.39$ & $1-16$ & 185 & $11.83 \pm 12.01$ & $1-64$ \\
\hline ESR1 & 55 & $3.33 \pm 0.90$ & $2-6$ & 184 & $4.36 \pm 1.31$ & $1-9$ & 184 & $8.89 \pm 4.00$ & $1-31$ \\
\hline PGRB & 55 & $4.45 \pm 1.25$ & $1-7$ & 181 & $5.19 \pm 1.67$ & $0-13$ & 182 & $7.26 \pm 6.51$ & $1-48$ \\
\hline CDH1 & 55 & $9.36 \pm 1.68$ & $4-13$ & 188 & $9.80 \pm 1.70$ & $4-15$ & 179 & $7.49 \pm 2.96$ & $1-20$ \\
\hline RASSF1A & 55 & $1.00 \pm 0.27$ & $0-2$ & 183 & $1.06 \pm 0.30$ & $0-3$ & 182 & $38.57 \pm 25.76$ & $1-88$ \\
\hline SYK & 55 & $1.16 \pm 0.37$ & $1-2$ & 183 & $1.55 \pm 0.64$ & $1-4$ & 184 & $6.02 \pm 4.32$ & $1-39$ \\
\hline TIMP3 & 55 & $2.93 \pm 1.35$ & $1-9$ & 183 & $3.04 \pm 1.95$ & $0-14$ & 175 & $6.14 \pm 7.38$ & $0-60$ \\
\hline BRMS1 & 55 & $1.31 \pm 0.66$ & $0-3$ & 182 & $1.68 \pm 1.04$ & $0-7$ & 183 & $3.20 \pm 1.59$ & $0-13$ \\
\hline SOCS1 & 55 & $1.04 \pm 0.38$ & $0-2$ & 183 & $1.45 \pm 0.79$ & $0-4$ & 184 & $5.02 \pm 3.45$ & $0-25$ \\
\hline
\end{tabular}

One third of all breast cancer patient display ER negative phenotype and to date it is still not clear if chromosomal alteration or mutations might be responsible for this phenotype. Moreover, changes in the ER tumor expression status were observed, when the ER positive tumors became ER negative during the patient treatment. Hypermethylation in the promoter region of the gene ESR1 represents one of the possible mechanisms for loss of ESR1 gene expression since methylation represents a reversible and dynamic process. The expressions of ER and PR receptors need to be monitored to identify patients that will positively respond to hormonal antiestogen treatment $[8,9]$.

In our results, the values of ESRI gene methylation in paraffin embedded tumor tissue were relatively low and ranged from 1-31\% among the individual patients (Figure 1) with average value $8.89 \% \pm 4.00$. Average value of methylation measured in patients peripheral blood lymphocytes is $4.36 \% \pm$ 1.31 (range of 1-9 \%) which is just slightly higher when compared to healthy controls $3.33 \pm 0.90 \%$ (range 2-6\%). In similar study reported by other authors the aberrant DNA methylation was not detected in gene ESRI [4, 9]. In contrast to the authors who have demonstrated significant levels of DNA methylation in gene ESRI [11, 12, 13], we have analyzed the higher number of $\mathrm{CpG}$ dinucleotides in the ESRI gene and we used pyrosequencing as more sensitive quantitative method for analyzing methylation of specific $\mathrm{CpG}$ dinucleotides. The average values of methylation in studied tumor samples of the 131 ER positive and 29 ER negative patients were $8.76 \% \pm 4.065$ (range $1-31 \%$ ) and $9 \% \pm 3.625$ (range 2-16\%), respectively. These methylation levels are nearly identical, and they are most likely not responsible for partial or complete inhibition of gene expression. In literature, complete absence of $A D A M 23$ tumor suppressor gene expression was observed for breast cancer patients with the DNA methylation levels in range of 40-60\% [14], and for 
colorectal cancer patients in range of 70-90\% [15]. Based on these findings we can conclude that low level of ESRI gene methylation we identified in analyzed tumor samples is not responsible for the lack of ER expression. The relationship between ESRl promoter methylation and ER expression was statistically not significant with $\mathrm{P}=0.464$. ER expression in the tumor ranged from $0-100 \%$. It is currently estimated that the immunohistochemical determination of estrogen receptor expression is determined incorrect (false positive or false negative) in up to $20 \%$ of cases a worldwide. The subjective evaluation of positive stained cells and the staining intensity of the signal, and also definition of thresholds for ER positive and negative tumors could be the reasons of this mistake. Tumors were considered to be positive tumors in case of at least $1 \%$ of the tumor tissue cells shown immunoreactivity.

Some studies indicate that also other mechanisms regulating ESRI gene expression may be involved, such as aberrant miRNA regulation and posttranscriptional modifications of histones [16]. MicroRNAs are small noncoding RNAs that suppress post-transcriptional gene expression by pairing with the 3 'UTR of target mRNAs. Several studies have demonstrated a correlation between microRNA-212/222 and ER expression. Over-expression of microRNA-212/222 in ER positive breast tumors showed a suppression of expression of ER and other proteins [17]. Also reduction of the histone deacetylase HDAC1 level in advanced stage cancer associated with negative expression of ER has been described in regard to the status of estrogen receptors of breast carcinomas [18].

The data obtained for the progesterone receptor PR were as follows: average values of methylation in tumor tissue $7.26 \pm 6.51 \%$ (range $1-48 \%$ ), in peripheral blood lymphocytes of patients $5.19 \% \pm 1.67$ (range 0-13\%) and in healthy controls, $4.45 \% \pm 1.25$ (range 1-7\%). Although the significant correlation between the level of methylation and expression of progesterone receptor was found in tumor of the patients $(\mathrm{P}=0.020)$, the mean DNA methylation values in tumor and peripheral blood cell in $P G R B$ are very similar and therefore the low DNA methylation of $P G R B$ gene could not initiate inhibition of relevant protein expression. It was demonstrated that expression of the two promoters in PGR $B$ gene is induced by the ER in function of transcription factor [19]. It suggests that in ER negative patients, the progesterone receptor should not be expressed, independently on methylation status.

In our study the variable expression profiles in all analyzed genes ranging from negative expression to high expression were found, but no relationship with biological significance between DNA methylation and protein expression was demonstrated. 
Figure 1. Expression of ER receptors in normal breast tissue and invasive ductal carcinoma of the ER negative patient with low/normal DNA methylation.

A: Normal breast tissue with focal expression of ER. Immunohistochemical staining with antibody against ER. Magnification $300 x$.

B: Invasive ductal carcinoma of the breast. Negative immunohistochemical staining with antibody against ER. Magnification $300 x$.

$C$ : Pyrosequencing result of the ESRI gene promoter $A$ region 1 with average DNA methylation in the tumor of $11 \%$.

D: Pyrosequencing result of the ESR1 gene promoter A region 2 with average DNA methylation in the tumor of $4 \%$.

A

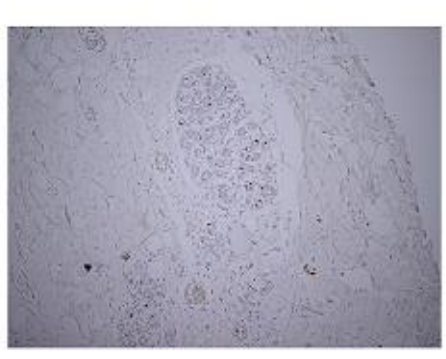

B

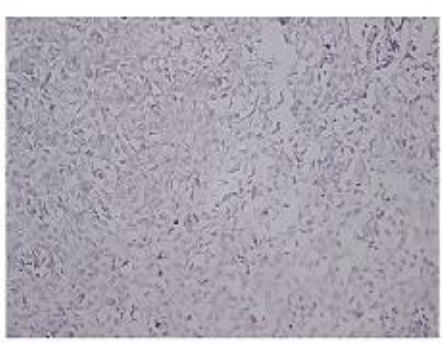

C

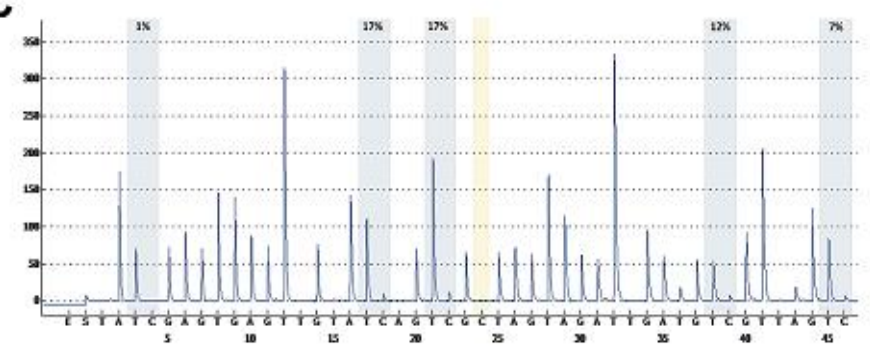

D

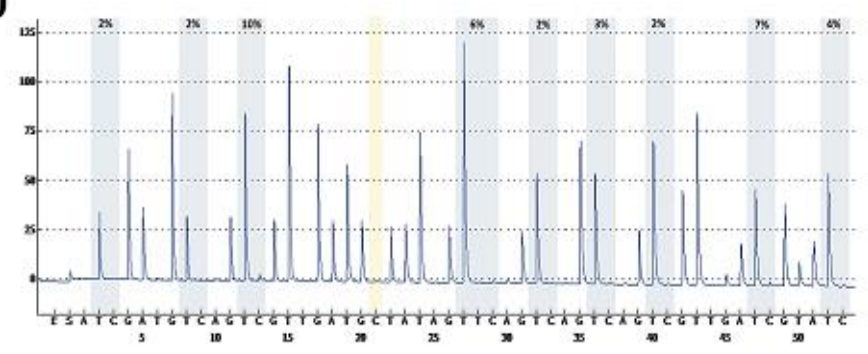

\section{Conclusion}

Breast cancer is a heterogeneous disease for which alterations in DNA methylation patterns have been shown to be of biological and clinical importance. We can conclude that the quantitative analyses of tumor DNA methylation in any of RASSF1A, ADAM23, CXCL12 and APC genes could have prognostic potential.

Surprisingly, the determination of methylation in genes ESR 1 and PGR B encoded hormonal receptors have not a relevant for prognosis or development of the disease.

Identification of early epigenetic changes in breast cancer might give valuable markers for early detection and contribute to the understanding of how these changes affect the progression of the disease and prognosis for the patient. 


\section{References}

1. http://www.cancerresearchuk.org/cancer-info/cancerstats/world/incidence/\#Com $\underline{\text { mon }}$

2. Fleischer, T., Edvardsen, H., Solvang, H.K., Daviaud, C., Naume, B., BørresenDale, A.L, Kristensen, V.N., Tost, J. 2014. Integrated analysis of highresolution DNA methylation profiles, gene expression, germline genotypes and clinical end points in breast cancer patients. Int. J. Cancer 134, 11 (Jun 2014), 2615-25. DOI= http://dx.doi.org/10.1002/ijc.28606. Epub 2014 Jan 6.

3. Cho, Y.H., Shen, J., Gammon, M.D., Zhang, Y.J., Wang, Q. 2012. Prognostic significance of gene specific promoter hypermethylation in breast cancer patients. Breast Cancer Res. Treat. 131, 1 (Jan. 2012), 197-205. DOI= http://dx.doi.org/ 10.1007/s10549-011-1712-y.

4. Gaudet, M.M., Campan, M., Figueroa, J.D., Yang, X.R., Lissowska, J., Peplonska, B., Brinton, L.A., Rimm, D.L., Laird, P.W., Garcia-Closas, M., Sherman, M.E. 2009. DNA hypermethylation of ESR1 and PGR in breast cancer: pathologic and epidemiologic associations. Cancer Epidemiol.Biomarkers Prev. 18, 11 (Nov. 2009), 3036-3043. DOI= http://dx.doi.org/10.1158/1055-9965.EPI-09-0678.

5. Ramos, E.A., Camargo, A.A., Braun, K., Slowik, R., Cavalli, I.J. 2010. Simultaneous CXCL12 and ESR1 CpG island hypermethylation correlates with poor prognosis in sporadic breast cancer. BMC Cancer 28, 10 (Jan. 2010), 23. DOI= http:// dx.doi.org/10.1186/1471-2407-10-23.

6. Metge, B.J., Frost, A.R., King, J.A., Dyess, D.L., Welch, D.R. 2008. Epigenetic silencing contributes to the loss of BRMS1expression in breast cancer. Clin. Exp. Metastasis 25, 7, 753-63. DOI= http://dx.doi.org/10.1007/s10585-008-9187-x.

7. Zmetakova, I., Danihel, L., Smolkova, B., Mego, M., Kajabova, V., Krivulcik, T., Rusnak, I., Rychly, B., Danis, D., Repiska, V., Blasko, P., Karaba, M., Benca, J., Pechan, J., Fridrichova, I. 2013. Evaluation of protein expression and DNA methylation profiles detected by pyrosequencing in invasive breast cancer. Neoplasma 60, 6, 635-46. DOI= http://dx.doi.org/10.4149/neo 2013082.

8. McGuire, W. L. 1978. Hormone receptors: their role in predicting prognosis and response to endocrine therapy. Semin. Oncol. 5, 4 (Dec. 1994), 428-433.

9. Lapidus, R. G., Nass, S. J., Davidson, N. E. 1998. The Loss of Estrogen and Progesterone Receptor Gene Expression in Human Breast Cancer. J. Mammary Gland. Biol. 3, 1 (Jan. 1998), 85-94. DOI=http://www.ncbi.nlm.nih.gov/pubmed/ ?term

10. Muggerud, A.A., Rønneberg, J.A., Wärnberg, F., Botling, J., Busato, F., Jovanovic, J., Solvang, H., Bukholm, I., Børresen-Dale, A.L., Kristensen, V.N., Sørlie, T., Tost, J. 2010. Frequent aberrant DNA methylation of ABCB1, FOXC1, PPP2R2B and PTEN in ductal carcinoma in situ and early invasive breast cancer. Breast Cancer Res. 12, 1, R3. DOI= http://dx.doi.org/ $10.1186 /$ bcr 2466.

11. Lapidus, R.G., Ferguson, A.T., Ottaviano, Y.L., Parl, F.F., Smith, H.S., Weitzman, S.A., Baylin, S.B., Issa, J.-P., Davidson, N.E. 1996. Methylation of estrogen and progesterone receptor gene $5^{\prime} \mathrm{CpG}$ islands correlates with lack of estrogen and progesterone receptor gene expression in breast tumors. Clin. Cancer Res. 2, 5 (May 1996), 805-810.

12. Yoshida, T., Eguchi, H., Nakachi, K., Tanimoto, K., Higashi, Y., Suemasu, K., Iino, Y., Morishita, Y., Hayashi, S. 2000. Distinct mechanisms of loss of estrogen receptor alpha gene expression in human breast cancer: methylation of the gene 
and alteration of trans-acting factors. Carcinogenesis 21,12 (Dec. 2000), 21932201.

13. Mirza, S., Sharma, G., Prasad, C.P., Parshad, R., Srivastava, A., Gupta, S.D., Ralhan, R. 2007. Promoter hypermethylation of TMS1, BRCA1, ER $\alpha$ and PRB in serum and tumor DNA of invasive ductal breast carcinoma patients. Life Sci. 81, 4 (Jul 2007), 280-287.

14. Costa, F.F., Verbisck, N.V., Salim, A.C., Ierardi, D.F., Pires, L.C., Sasahara, R.M., Sogayar, M.C., Zanata, S.M., Mackay, A., O'Hare, M., Soares, F., Simpson, A.J., Camargo, A.A. 2004. Epigenetic silencing of the adhesion molecule ADAM23 is highly frequent in breast tumors. Oncogene 23,7 (Feb. 2004), 1481-1488.

15. Choi, J.S., Kim, K.H., Jeon, Y.K., Kim, S.H., Jang, S.G., Ku, J.L., Park, J.G. 2009. Promoter hypermethylation of the ADAM23 gene in colorectal cancer cell lines and cancer tissues. Int. J. Cancer 124, 6 (May 2009), 1258-1262. DOI= http://dx.doi.org/10.1002/ijc.24023.

16. Leu, Y.W., Yan, P.S., Fan, M., 2004. Loss of estrogen receptor signaling triggers epigenetic silencing of downstream targets in breast cancer. Cancer Res. 64, 22, (Nov 2004), 8184-8192.

17. Zhao, J.J., Lin, J., Yang, H., Kong, W., He, L., Ma, X., Coppola, D., Cheng, J.Q. 2008. MicroRNA-221/222 negatively regulates estrogen receptor alpha and is associated with tamoxifen resistance in breast cancer. J. Biol. Chem. 283, 45 (Nov. 2008), 31079-31086. DOI= http://dx.doi.org/10.1074/jbc.M806041200.

18. Suzuki, J., Chen, Y. Y., Scott, G. K., Devries, S., Chin, K., Benz, C.C., Waldman, F.M., Hwang, E.S. 2009. Protein acetylation and histone deacetylase expression associated with malignant breast cancer progression. Clin. Cancer. Res. 15, 9 (May 2009), 3163-3171.

19. Kastner, P., Krust, A., Turcotte, B., Stropp, U., Tora, L., Gronemeyer, H., Chambon, P. 1990. Two distinct estrogen-regulated promoters generate transcripts encoding the two functionally different human progesterone receptor forms A and B. EMBO J. 9, 5 (May 1990), 1603-1614. 